\title{
Clinical Case of a Transfusion-Associated Canine Mycoplasma haemocanis Infection in the Republic of Korea: A Case Report
}

\author{
Jihu Kim¹, Donghwan Lee', Eunchae Yoon', Hyeona Bae', Daseul Chun', Jun-Gu Kang², Dong-In Jung1, \\ Do-Hyeon $\mathrm{Yu}^{1, *}$ (i) \\ ${ }^{1}$ College of Veterinary Medicine, Gyeongsang National University, Jinju 52828, Korea; ${ }^{2}$ Korea Zoonosis Research Institute, Jeonbuk National \\ University, Iksan 54531, Korea
}

\begin{abstract}
This report describes the first clinical case of a transfusion-associated Mycoplasma haemocanis infection in a dog in Korea. A 6-year-old male Maltese underwent a red blood cell transfusion for idiopathic immune-mediated hemoIytic anemia. Eighteen days after the blood transfusion, the recipient's packed cell volume decreased and basophilic organisms were found on erythrocytes. A polymerase chain reaction and sequential analysis showed that both the donor dog and recipient dog had $M$. haemocanis. Six weeks after doxycycline administration, no organisms were detected and the recipient's anemia had improved.
\end{abstract}

Key words: Mycoplasma haemocanis, blood transfusion, donor, hemolytic anemia

\section{INTRODUCTION}

Mycoplasma haemocanis is the main pathogen of hemotropic mycoplasmas (hemoplasma) in dogs and comprises a group of bacteria that parasitize the surface of erythrocytes. These species are transmitted by blood-sucking arthropods, such as ticks $[1,2]$. M. haemocanis has been molecularly detected in 1 out of $510(0.2 \%)$ healthy dogs in Korea [2]. However, until now, there have been no clinical reports of M. haemocanis in dogs in Korea. We report a clinical case of M. haemocanis infection in a dog in Korea. The hematologic and cytologic analyses results were consistent with $M$. haemocanis infection, and the molecular analysis results confirmed the presence of the organism.

\section{CASE DESCRIPTION}

A 6-year-old male Maltese dog presented with sudden lethargy and anorexia for 3 days. The dog had a pale mucous

\footnotetext{
- Received 8 May 2020, revised 4 August 2020, accepted 12 August 2020.

*Corresponding author (yudh@gnu.ac.kr)

(C) 2020, Korean Society for Parasitology and Tropical Medicine

This is an Open Access article distributed under the terms of the Creative Commons

Attribution Non-Commercial License (https://creativecommons.org/licenses/by-nc/4.0) which permits unrestricted non-commercial use, distribution, and reproduction in any

medium, provided the original work is properly cited.
}

membrane and tachycardia, and his manual packed cell volume (mPCV) was $11 \%$, with a total solid volume of $7 \mathrm{mg} / \mathrm{dl}$. Remarkable spherocytosis (13/high-power field) with autoagglutination after saline dilution (Fig. 1A) supported the diagnosis of immune-mediated hemolytic anemia (IMHA). The dog was an indoor dog with no history of exposure to ticks or fleas. To completely exclude infectious hemolytic anemia, a tick/vector comprehensive real-time polymerase chain reaction panel (IDEXX, Westbrook, Maine, USA) for Mycoplasma haemocanis, Babesia spp., Ehrlichia spp., Anaplasma spp., Rickettsia spp., and Hepatozoon spp. of an ethylenediamine tetra-acetic acid-anticoagulated blood sample was performed; all the results were negative. Leukocytosis $\left(36.73 \times 10^{3} / \mu \mathrm{l}\right.$; reference range, 5.05$\left.16.76 \times 10^{3} / \mu \mathrm{l}\right)$ with neutrophilia $\left(31.23 \times 10^{3} / \mu \mathrm{l}\right.$; reference range, $\left.2.95-11.64 \times 10^{3} / \mu \mathrm{l}\right)$, monocytosis $\left(2.03 \times 10^{3} / \mu \mathrm{l}\right.$; reference range, $\left.0.16-1.12 \times 10^{3} / \mu l\right)$, and eosinopenia $\left(0.04 \times 10^{3} /\right.$ $\mu \mathrm{l}$; reference range, $0.06-1.23 \times 10^{3} / \mathrm{\mu l}$ ) suggested a stress leukogram. Serum biochemistry showed hyperbilirubinemia (4 mg/ $\mathrm{dl}$; reference range, 0-0.9 mg/dl), increased blood urea nitrogen $(30 \mathrm{mg} / \mathrm{dl}$; reference range, $7-27 \mathrm{mg} / \mathrm{dl}$ ), and hyperlactatemia (6 mmol/L; reference range, $0-2 \mathrm{mmol} / \mathrm{L}$ ) (Table 1$)$. Testing to determine exposure to drugs, toxins, and ectoparasites yielded negative results; therefore, primary idiopathic IMHA was diagnosed. As an emergency treatment, a commercial packed red blood cell (Korea Animal Blood Bank, Sokcho, Korea) trans- 


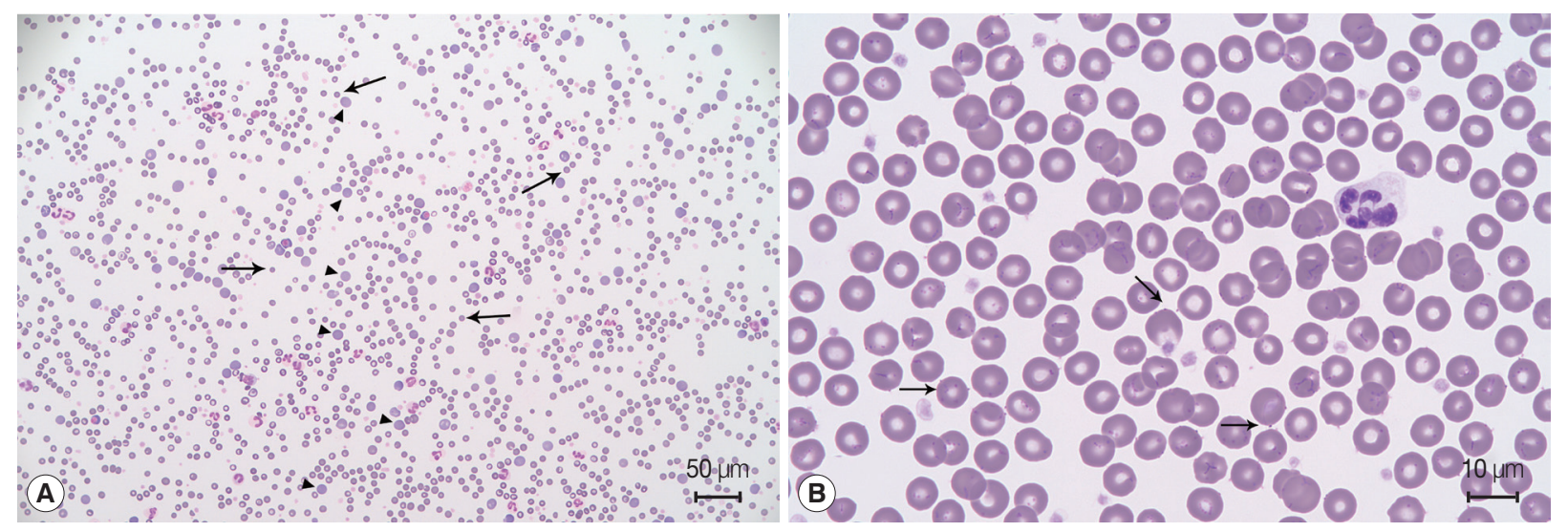

Fig. 1. Blood film examination. (A) Spherocytosis (arrow), polychromasia (arrowhead), and agglutination of the red blood cells indicate immune-mediated hemolytic anemia. Diff-Quik staining. (B) Basophilic organisms located on the surface of erythrocytes (arrow). Some erythrocytes have many organisms forming filamentous chains in the deep grooves on their surfaces. Diff-Quik staining.

Table 1. Clinical parameters of this case

\begin{tabular}{|c|c|c|c|c|c|c|c|c|}
\hline & \multirow[b]{2}{*}{ Reference range } & \multicolumn{7}{|c|}{ Date } \\
\hline & & Day -24 & $\begin{array}{c}\text { Day-23 } \\
\text { (first transfusion) }\end{array}$ & Day -12 & Day 0 & $\begin{array}{c}\text { Day } 1 \\
\text { (second transfusion) }\end{array}$ & Day 19 & Day 34 \\
\hline PCV (\%) & $37.3-61.7$ & 11 & 30 & 18 & 9 & 43 & 19.5 & 32.5 \\
\hline Spherocytes (cells/hpf) & & 13 & 8 & 12 & 7 & 7 & 25 & 6 \\
\hline WBC $\left(10^{3} / \mu l\right)$ & $5.05-16.76$ & 36.73 & 34.35 & 26.4 & 28.24 & 12.79 & 34.61 & 13.1 \\
\hline Platelet count $\left(10^{3} / \mu \mathrm{l}\right)$ & $148-484$ & 155 & 56 & 319 & 578 & 275 & 114 & 462 \\
\hline Bilirubin (mg/dl) & 0-0.9 & 4 & 1 & 0.3 & & & & 0.1 \\
\hline Blood urea nitrogen (mg/dl) & $7-27$ & 30 & 13 & & & & & \\
\hline
\end{tabular}

hpf, high-power field; PCV, packed cell volume; WBC, white blood cells.

fusion was initiated. Blood typing was not performed at that time because it was the first transfusion for this dog.

After the first blood transfusion, the dog's mPCV increased from $11 \%$ to $30 \%$, and he responded well to prednisolone (Solondo ${ }^{\circledR}$; Yuhan Medica, Seoul, Korea) $1 \mathrm{mg} / \mathrm{kg}$ orally every $24 \mathrm{hr}$ and mycophenolate mofetil (Cellcept ${ }^{\circledR ;}$; Roche Pharmaceuticals, Basel, Switzerland) $10 \mathrm{mg} / \mathrm{kg}$ orally every $12 \mathrm{hr}$ as immunosuppressive agents, and to clopidogrel (Pravix ${ }^{\circledR ;}$; Sinil Pharm, Seoul, Korea) $2 \mathrm{mg} / \mathrm{kg}$ orally every $24 \mathrm{hr}$ as the antiplatelet agent. The clinical signs and laboratory analyses results remained stable for more than 1 week.

Twenty-five days after the first transfusion, the dog's mPCV decreased to 9\%; therefore, a second blood transfusion was needed. The immunochromatographic blood typing test (Quick Test Blood Typing; Alvedia, Limonest, France) revealed that the dog had erythrocyte antigen (DEA)-1-negative blood. Because it was impossible to obtain DEA-1-negative blood from the commercial blood bank in Korea, packed red blood cells (RBC) were collected from a clinic-owned dog used as a blood donor. The donor lived indoors but was occasionally exposed to the outdoors; furthermore, it had undergone regular control of ectoparasites and was negative for Dirofilaria immitis, Ehrlichia canis, Anaplasma phagocytophilum, and Borrelia burgdorferi according to the SNAP 4Dx test kit (SNAP 4Dx Plus Test; IDEXX), and for Babesia gibsoni using an in-house polymerase chain reaction (PCR) [3] before transfusion. M. haemocanis was not considered because its existence has been unclear in Korea. In-house leukoreduced-packed RBC from the donor was prepared using a closed collection and filter system (Blood Bag with RBC Filter and Safety DDA Plus 3 Quadruple $400 \mathrm{ml}$; Tae-Chang Industrial, Daegu, Korea) [4]. The mPCV of the recipient dog was $36 \%$ after the blood transfusion. No reactions to the transfusion occurred during hospitalization.

Eighteen days after the second blood transfusion, the mPCV decreased to $19.5 \%$. Moreover, a blood film indicated that basophilic organisms were attached to the external surfaces of the erythrocytes (Fig. 1B). Leukocytosis $\left(34.61 \times 10^{3} / \mu \mathrm{l}\right.$; reference range, $\left.5.05-16.76 \times 10^{3} / \mu \mathrm{l}\right)$ and thrombocytopenia (114 $\times$ 


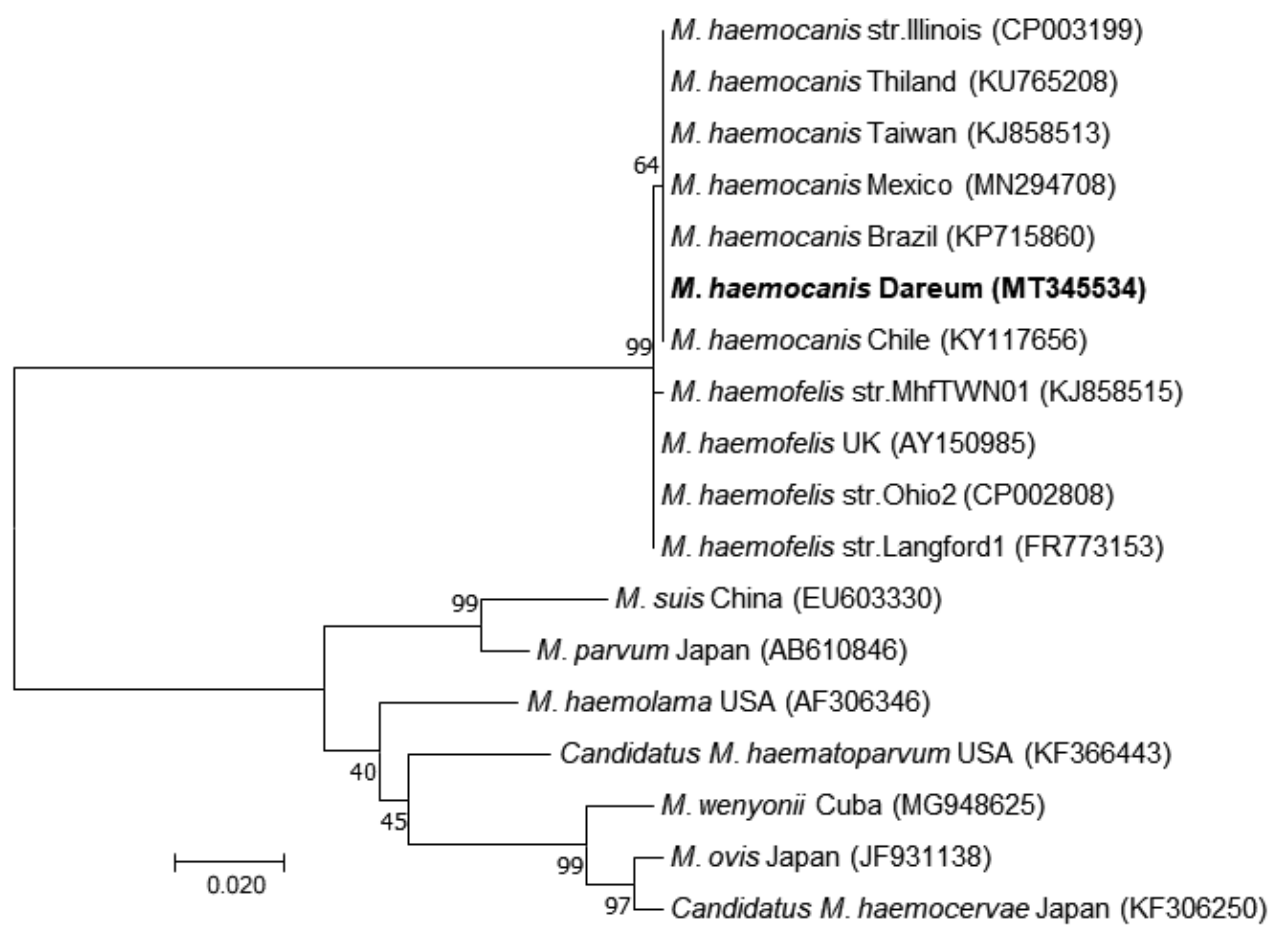

Fig. 2. Molecular phylogenetic tree generated using the maximum likelihood method, showing a position of Mycoplasma haemocanis obtained from the recipient of this case. The acquired 588-bp sequence was aligned using Clustal X (version 2.1) and analyzed with MEGA 7. The phylogenetic trees were constructed using a maximum likelihood method based on the Kimura 2-parameter model. The percentage of trees in which the associated taxa clustered together is shown next to the branches. The initial tree(s) during the heuristic search were obtained automatically by applying neighbor-joining and BIONJ algorithms to a matrix of pairwise distances estimated using the maximum composite likelihood approach and then selecting the topology with the superior log likelihood value. A total of 585 positions were in the final dataset.

$10^{3} / \mu \mathrm{l}$; reference range, $\left.148-484 \times 10^{3} / \mu \mathrm{l}\right)$, which were not observed 7 days previously, were also present. Based on these results, M. haemocanis infection was suspected. PCR analyses [5] were performed in the laboratory to detect Mycoplasma species from the donor and the recipient, and the results showed that M. haemocanis DNA was amplified in both the donor and recipient blood samples. A sequence analysis of these amplified products confirmed that the products were from the M. haemocanis $16 \mathrm{~S}$ rRNA gene. The partial sequence was deposited into the GenBank and assigned the accession number MT345534. The obtained $16 \mathrm{~S}$ rRNA sequences from both dogs were identical to each other and to other M. haemocanis sequences reported by several other countries, such as Chile (KY117858), Brazil (KP715860), and Mexico (MN294708). Moreover, they were 99.83\% homologous with Mycoplasma haemofelis sequences obtained from Ohio2 (CP002808) and Langford1 (FR773153) strains (Fig. 2).

Both dogs were treated with doxycycline (Doxycycline Hyclate ${ }^{\circledR}$; Kukje Pharm, Seongnam, Korea) 5 mg/kg orally every 12 hr for 6 weeks. After this time, the clinical signs of the recipient were normal and the PCR test results were no longer positive.

\section{DISCUSSION}

This is the first case report of M. haemocanis diagnosed in a dog in Korea using a molecular analysis, blood film, and clinical signs. It is also the first to confirm the treatment results of antibiotics used to manage the disease in a dog.

Until now, 2 reports of molecular detection of M. haemocanis in Korea have been published. In one study, only 1 out of 510 randomly selected healthy dogs in Korea was infected with M. haemocanis according to sequential confirmation after DNA amplification [2]. However, another study performed in 2017 indicated that 168 out of 440 Korean outdoor dogs (38.2\%) were confirmed to have $M$. haemocanis infection, as evidenced by multiplex PCR [6] testing performed by a reference laboratory; however, sequential confirmation was not performed. The sample selection and methodological differences might have contributed to the differing prevalence. However, to the 
best of our knowledge, no clinical reports of $M$. haemocanis in dogs in Korea have been published.

The natural mode of transmission of canine hemoplasmas has not been definitively elucidated; however, it has been observed that blood transfusions, blood-sucking arthropods, and, more recently, mange mites might be involved [7]. Rhipicephalus sanguineus and Ixodes spp. have been indicated as the major vectors; however, a very low population of these ticks infest dogs in Korea $[8,9]$. Therefore, a broad-spectrum study of M. haemocanis transmission should be performed in the future.

The route of M. haemocanis infection was a blood transfusion in our case. Even though the pathogen screening test results of the donor comprise an important part of the transfusion protocol, there is no consensus regarding veterinary donor screening in Korea. A simple diagnostic kit and standard PCR analysis are practical methods used by most veterinary clinicians to analyze the blood of the donor. The 2016 American College of Veterinary Internal Medicine consensus statement recommends the type of blood-borne pathogens that should be the focus of screening [10]. Blood transfusions for companion animals are increasing in Korea; therefore, it is necessary to introduce bloodborne pathogen screening criteria for donors. M. haemocanis should be included in the screening because its transmission through the blood transfusion resulted in the infection in this case.

The clinical scenario of the M. haemocanis infection was similar to that reported previously: severe hemolytic anemia occurred 2 weeks after the blood transfusion and the infection was wellmanaged with doxycycline administration. A previous study reported a 9-year-old female spayed Golden Retriever that received a blood transfusion from an unscreened donor during splenectomy and exhibited weakness, marked regenerative anemia, and distinct inclusions on the surface of red blood cells 29 days after surgery. The recipient dog was diagnosed with M. haemocanis and treated with tetracycline [11]. Even though the infection was subclinical in the donor, it was fatal in the recipient dog because of immunosuppression and IMHA.

In this case, doxycycline alone was used to treat the infection for 6 weeks, and both the donor and recipient were finally confirmed as M. haemocanis-negative. However, the study would have been improved if we had monitored the responsiveness to the antibiotics as well as the clinical improvements and hematological changes. No studies have clearly suggested the efficiency, duration, withdrawal period, and monitoring criteria for treatment. A previous study showed that quantitative real-time PCR monitoring objectively indicated when to withdraw antibiotic therapy and what types of antibiotics were most effective for treating M. haemocanis in a dog [12]. It also emphasized the need for more objective monitoring indicators because the relationship between the presence of an inclusion body in the blood smear and the agent copy number was not significant [12].

In summary, we confirmed anemia due to M. haemocanis infection resulting from a blood transfusion in an immunosuppressed dog. Moreover, the results of treatment with antibiotics were confirmed at the molecular level using PCR. This is the first report of diagnosing and treating $M$. haemocanis in a dog in Korea. An official blood transfusion system and donor screening criteria should be established in Korea. Because M. haemocanis was detected, this pathogen should be included in these criteria.

\section{ACKNOWLEDGMENT}

This research was supported by the Basic Science Research Program through the National Research Foundation of Korea (NRF) funded by the Ministry of Science, ICT \& Future Planning (2020R1C1C1008675).

\section{CONFLICT OF INTEREST}

All authors declare no conflict of interest.

\section{REFERENCES}

1. Messick JB. Hemotrophic mycoplasmas (hemoplasmas): a review and new insights into pathogenic potential. Vet Clin Pathol 2004; 33: 2-13.

2. Seo MG, Kwon OD, Kwak D. Molecular detection and phylogenetic analysis of canine tick-borne pathogens from Korea. Ticks Tick Borne Dis 2020; 11: 101357.

3. Lee MJ, Yu DH, Yoon JS, Li YH, Lee JH, Chae JS, Park J. Epidemiologic and clinical surveys in dogs infected with Babesia gibsoni in South Korea. Vector Borne Zoonotic Dis 2009; 9: 681-686.

4. Yang H, Kim W, Bae J, Kim H, Kim S, Choi J, Park J, Jung DI, Koh HB, Yu DH. Effects of irradiation and leukoreduction on down-regulation of CXCL-8 and storage lesion in stored canine whole blood. J Vet Sci 2019; 20: 72-78.

5. Varanat M, Maggi RG, Linder KE, Breitschwerdt EB. Molecular prevalence of Bartonella, Babesia, and hemotropic Mycoplasma sp. in dogs with splenic disease. J Vet Intern Med 2011; 25: 1284- 
1291.

6. Suh GH, Ahn KS, Ahn JH, Kim HJ, Leutenegger C, Shin SS. Serological and molecular prevalence of canine vector-borne diseases (CVBDs) in Korea. Parasit Vectors 2017; 10: 146.

7. Willi B, Novacco M, Meli M, Wolf-Jäckel G, Boretti F, Wengi N, Lutz H, Hofmann-Lehmann R. Haemotropic mycoplasmas of cats and dogs: transmission, diagnosis, prevalence and importance in Europe. Schweiz Arch Tierheilkd 2010; 152: 237-244.

8. Chae JS, Yu DH, Shringi S, Klein TA, Kim HC, Chong ST, Lee IY, Foley J. Microbial pathogens in ticks, rodents and a shrew in northern Gyeonggi-do near the DMZ, Korea. J Vet Sci 2008; 9: 285-293.

9. Kim CM, Yi YH, Yu DH, Lee MJ, Cho MR, Desai AR, Shringi S, Klein TA, Kim HC, Song JW, Baek LJ, Chong ST, O'Guinn M L, Lee JS, Lee IY, Park JH, Foley J, Chae JS. Tick-borne rickettsial pathogens in ticks and small mammals in Korea. Appl Environ Microbiol 2006; 72: 5766-5776.

10. Wardrop KJ, Birkenheuer A, Blais MC, Callan MB, Kohn B, Lappin MR, Sykes J. Update on Canine and Feline Blood Donor Screening for Blood-Borne Pathogens. J Vet Intern Med 2016; 30: 15-35.

11. Lester SJ, Hume JB, Phipps B. Haemobartonella canis infection following splenectomy and transfusion. Can Vet J 1995; 36: 444445.

12. Hulme-Moir KL, Barker EN, Stonelake A, Helps CR, Tasker S. Use of real-time quantitative polymerase chain reaction to monitor antibiotic therapy in a dog with naturally acquired Mycoplasma haemocanis infection. J Vet Diagn Invest 2010; 22: 582587. 
